\title{
Applications of maintenance optimization models: a review and analysis
}

\author{
Rommert Dekker \\ Erasmus University, Rotterdam, The Netherlands
}

\begin{abstract}
In this paper we give an overview of applications of maintenance optimization models published so far. We analyze the role of these models in maintenance and discuss the factors which may have hampered applications. Finally, we discuss future prospects. (C) 1996 Elsevier Science Limited.
\end{abstract}

\section{INTRODUCTION}

Throughout the years, the importance of the maintenance function, and therefore also of maintenance management, has grown. The widespread mechanization and automation has reduced the number of production personnel and has increased the capital employed in production equipment and civil structures. As a result, the fraction of employees working in the maintenance area has grown, as well as the fraction of maintenance spending on the total operational costs. In refineries, for instance, it is not uncommon that the maintenance and operations departments are the largest and that each comprises about $30 \%$ of total manpower. Furthermore, next to energy costs, maintenance spending can be the largest part of the operational budget (see Ref. 113). Yet, the main question faced by maintenance management, whether its output is produced both effectively, in terms of contribution to company profits, and efficiently, in terms of manpower and materials employed, is very difficult to answer.

In theory, maintenance management, facing these problems, could have benefited from the advent of a large area in operations research, called maintenance optimization. This area was founded in the early sixties by researchers like Barlow, Proschan, Jorgenson, McCall, Radner and Hunter, whose results are nicely summarized in the review by $\mathrm{McCall}^{87}$ and the book from Barlow \& Proschan. ${ }^{5}$ Basically, a maintenance optimization model is a mathematical model in which both costs and benefits of maintenance are quantified and in which an optimum balance between both is obtained. Well-known models originating from this period are the so-called age and the block replacement models. Later on, the area proved to be fruitful for researchers. Reviews were made by Pierskalla \& Voelker, ${ }^{98}$ Bosch and Jensen, ${ }^{14}$ Sherif \& Smith ${ }^{109}$ and Sherif; ${ }^{110}$ the latter two even reporting on 524 and 818 articles respectively and many more have appeared since. Valdez-Flores \& Feldman ${ }^{118}$ report on more than 120 papers since 1982, while Cho \& Parlar $^{24}$ give the latest survey (on multi-unit models). Besides, many textbooks on operations research use replacement problems as examples.

Considering the foregoing, the following questions arise. First of all, what has been the value of maintenance optimization models for maintenance management? How often and in what sense have these models been applied successfully? Here, we do not focus on theoretical applications, but on applications yielding advice to management concerning maintenance on existing systems. In 1960 Mayer $^{86}$ and in 1967, Turban ${ }^{116}$ had already formulated the same question and concluded, after some research, that optimization models were applied in only a small minority of firms. As a quick glance indicates only a small number of applications (see Ref. 61), we also investigate what is needed for successful application of these models on maintenance problems and what presently constitutes the main bottlenecks. This analysis will also make clear to what extent future applications may be expected.

Our approach to these questions follows three routes. First of all, a literature search has been made on applications of maintenance optimization models and on tools developed to assist in maintenance optimization. Furthermore, discussions have been held with various people concerning the value of maintenance optimization models. Thirdly, the author has been involved with developing and implementing 
decision support systems for maintenance optimization. ${ }^{38}$ Combining information from all sides, a general evaluation of the value of maintenance optimization models as tools for management is given.

The structure of this paper is as follows. After a review of maintenance management, we introduce maintenance optimization models in Section 3. In Section 4 we present a review of applications and discuss bottlenecks for application in Section 5. This leads to future prospects which are dealt with in Section 6.

\section{MAINTENANCE MANAGEMENT}

\subsection{Objectives}

Maintenance can be defined as the combination of all technical and associated administrative actions intended to retain an item or system in, or restore it to, a state in which it can perform its required function. ${ }^{19}$ The maintenance objectives can be summarized under four headings-ensuring system function (availability, efficiency and product quality); ensuring system life (asset management); ensuring safety; ensuring human well-being.

For production equipment, ensuring the system function should be the prime maintenance objective. Here, maintenance has to provide the right (but not the maximum) reliability, availability, efficiency and capability (i.e., producing at the right quality) of production systems, in accordance with the need for these characteristics. In principle it is possible to give an economic value to the maintenance results, and a cost-balance can be done. Ensuring system life and asset management refers to keeping systems as such in proper conditions, whilst there are only indirect links to a possible production of goods or services. This objective is appropriate for civil structures, like buildings, dams, offshore platforms and roads, as their function is complex and not easy to measure. Often norms have to be set to define failure and the benefits of maintenance are therefore more difficult to quantify. In this case one has to minimize maintenance costs in order to meet the norms or conditions on states. Safety plays a role in case failures can have dramatic consequences, e.g., in the case of airplanes, nuclear and chemical plants. In this case testing and inspection activities constitute an important part of the maintenance work. Here, costs of maintenance have to be minimized while keeping the risks within strict limits and meeting statutory requirements. Finally, we refer to human well-being or shine as an objective, if there is no direct economic or technical necessity but primarily a psychological one (which indirectly may be economical). An example is painting which is not for protective reasons. This objective is the most difficult one to quantify.

\subsection{Historical overview}

Here we briefly mention some main trends in the history of maintenance management, following the reviews given by Kelly ${ }^{71}$ and Pintelon \& Gelders. ${ }^{(0)}$ The first scientific approaches to maintenance management date from the 1950's and 1960's. At that time preventive maintenance was advocated as a means to reduce failures and unplanned downtime. In many companies large time-based preventive maintenance programs were set-up. First operations research models for maintenance appeared in the sixties, attempting to optimize these programs. In the 1970 's condition monitoring came forward, focusing on techniques which predict failures using information on the actual state of equipment (e.g., luboil debris analysis, vibration monitoring). This proved to be more effective than the large time-based preventive maintenance programs. Detailed studies by manufacturers about the failures of their products resulted in better designs, with less failures as a result. In the 1980 's the computer was brought to the maintenance function. Initially most attention was paid to facilitating administrative processes, later on by making management information readily available (e.g., the registration of the causes for overtime); yet their influence on decision making has been limited. An important approach worth mentioning is Reliability Centred Maintenance (RCM), ${ }^{1}$ which was founded in the sixties and initially oriented towards airplane maintenance. It is only now, more than twenty years later, that it has started to break through in many industries. It directs maintenance efforts at those parts and units where reliability is critical. It can be regarded as the more qualitative approach to maintenance where optimization models are the quantitative approach, yet it is far more all-embracing than models which have only a limited applicability (see Ref. 58 for a comparison between costoptimization and RCM). Another, qualitative, approach which should be mentioned is Total Productive Maintenance, originating from Japan, which centres about solving maintenance problems using a quality circles method. ${ }^{95}$

\subsection{Comparing maintenance management with other management areas}

Maintenance has sometimes been described as the last frontier of scientific management. Lately it has attracted scientific attention and received greater status. The area is dominated by technically oriented people whose prime knowledge lies in solving 
technical problems (e.g., 'why did a pump fail?') and in managing people, but who are not familiar with reliability theory or operations research. Two aspects are typical for maintenance management.

First of all, maintenance faces an inherently stochastic deterioration and failure process. The state of affairs in a maintenance organization is often dominated by unplanned events. Failures of important equipment may delay long-planned activities. Major decisions, e.g., choosing between replacement or repair, may have to be taken quickly. Management, being under constant time pressure, therefore lacks time to become familiar with abstract management science techniques.

Secondly, maintenance consists of a multitude of different activities. At an individual activity level it is often difficult to quantify benefits of maintenance. Hence, at a macro level, it is very difficult to balance the maintenance budget with its contribution to company profits. Therefore, maintenance is often seen as a cost function only, with all associated negative implications.

\subsection{Problem hierarchies}

Thinking on maintenance should start in the design phase of systems. The type of equipment, the level of redundancy and the accessibility will then strongly effect the maintainability. When purchasing systems, future maintenance costs should be taken into account as well. To cover the costs over all phases of systems the life-cycle-costing concept was introduced. The maintenance concept or strategy describes what events (e.g., failure, passing of time) trigger what type of maintenance (inspection repair, replacement); it can be determined both after the design phase and in the operations phase. Most operations research models concentrate on this problem area. Once a system is in operation, maintenance has to be planned and scheduled. Here we denote by planning the determination of the execution moments of (major) maintenance activities, in accordance with other (e.g., production) plans (e.g., planning shutdowns of major refinery units), the work preparation and the determination of the required maintenance capacity. Scheduling of maintenance usually occurs at a shorter time horizon and consists of determining the order of execution of activities. It involves priority setting and using available manpower as efficiently as possible. Finally, there is maintenance control, which consists of comparing actuality with plans, indicating to management where problems are.

\subsection{Areas where maintenance is important}

Whenever there is a large amount of capital employed in technical systems, there will be a lot of maintenance (except, for example, space satellites, for obvious reasons). So, apart from the service sector, maintenance plays a large role in most sectors of society. Even in the software sector maintenance is growing in importance, but due to the special character of the systems to be maintained-softwarewe will leave it out of consideration in this paper. The medical sector can also be captured under the definition of maintenance, when humans are considered to be the systems of interest. Despite many similar concepts (e.g., lifetime distributions and screening for diseases corresponds to inspection), we will not consider this here either. The main industries considered are the oil and chemical industry, railways, transport companies, airlines, steelworks and the discrete parts manufacturers. Also considered are: the public sector, for example electricity generation; defence; and infrastructure, for example roads.

\section{MAINTENANCE OPTIMIZATION MODELS}

Here we define maintenance optimization models as those mathematical models whose aim it is to find the optimum balance between the costs and benefits of maintenance, while taking all kinds of constraints into account. In almost all cases, maintenance benefits consist of savings on costs which would be incurred otherwise (e.g., less failure costs). This definition does not include all operations research models applied in maintenance. Scheduling outages of electric power plants for maintenance is left out of consideration, unless typical maintenance aspects (like deterioration) are modelled explicitly. We exclude project management techniques, although some are used in shutdown planning of major installations in the process industry, as these lack the cost-benefit aspects of maintenance. We also exclude spare parts models as these primarily focus on inventory control.

In general, maintenance optimization models cover four aspects: (i) a description of a technical system, its function and its importance, (ii) a modelling of the deterioration of the system in time and possible consequences for the system, (iii) a description of the available information about the system and the actions open to management and (iv) an objective function and an optimization technique which helps in finding the best balance. For example, for the age replacement model the four aspects consist of: (i) 'one component, operating continuously', (ii) 'deterioration is not visible and failures occur suddenly, causing a loss of functioning', (iii) 'the component is replaced upon failure by an identical one against costs $c^{\prime}$ (including costs of loss of functioning) and preventively against costs $c^{p}$ (whenever it takes place), replacement times are recorded; a pdf $\mathrm{f}($.$) or a hazard$ rate $r($.$) as function of component age is known', (iv)$ 
objective functions are either the long-term average costs, or the long-term discounted costs; the renewal reward theorem provides an explicit formula for the objective function as a function of the replacement age, which may be minimized by a standard bisection method'.

Sherif \& Smith $^{109}$ classify the models according to the modelling of the deterioration into:

1. Deterministic Models

2. Stochastic Models

A. Under Risk

B. Under Uncertainty.

They further distinguish between a simple system (single component) and a complex system. The difference between risk and uncertainty is that in case of risk it is assumed that a probability distribution of the time to failure is available, which is not so in the case of uncertainty. The latter therefore includes models with adaptive policies. The optimization methods employed include linear and nonlinear programming, dynamic programming, Markov decision methods, decision analysis techniques, search techniques and heuristic approaches.

Maintenance optimization models yield various results. First of all, policies can be evaluated and compared with respect to cost-effectiveness and reliability characteristics. Secondly, results can be obtained on the structure of optimal polices, like the existence of an optimal control-limit policy. Thirdly, models can assist in the timing aspect: how often to inspect or to maintain. These results all refer to the maintenance concept; the last one also to maintenance planning. Finally, models can also be of help in determining effective and efficient schedules and plans, taking all kind of constraints into account.

\section{A REVIEW OF APPLICATIONS}

\subsection{Introduction}

As models may be applied in several ways, we will make the following distinctions. A paper is classified as a case study if (maintenance optimization) models have been used with real data to provide advice to management on a real problem. A second type of paper is one in which a new model is put central, but in which indications are given about (not just possible, but real) applications of the model. This can occur in several ways, varying from just suggesting applications or overviewing real applications to showing examples with real data. The last type of paper is that which focuses on an application tool, like a decision support system or expert system and which mentions applications of the tool.

A literature search was conducted in the database INSPEC using the search words 'maintenance', 'replacement', 'repair', 'optimization' and 'application(s)' or 'case study/ies'. This resulted in some fifteen papers. Next, we wrote to a number of leading experts asking them about applications. Then we traced as many references on applications as possible. A problem encountered in this respect was that practitioners more often publish in proceedings than in regular scientific journals, yet this category is far more difficult to trace and is often not covered by the regular databases, like INSPEC.

\subsection{Applications}

The number of real case studies found was 43 . [References: 3, 6-8, 13, 15, 16, 18, 20, 23, 25-32, 35, $46,49,55,59,63-65,69,79,84,89,92,93,96,99,101$, $106,111,114,115,117,120,123,128$.] Furthermore, there are 22 papers which present a model and apply it to real data [Refs $11,21,22,34,40,44,45,52,57$, $76,82,83,85,91,94,97,104,105,108,112,121,131]$ and 8 papers which give some overview and give some discussion of case studies [Refs 10,17, 33, 47, 48, 60, $75,78]$. There are 26 papers which focus on a model and state that it has been applied to a real case, without giving further details (like data) [Refs 2, 9, 12, $36,37,39,41,42,53,56,62,67,68,70,72,74,77,81$, $88,90,102,103,107,126,129,132]$. Finally, there are 14 papers (including 4 which also present a real case) describing an application tool and mention its application [Refs 38, 43, 51, 54, 65, 66, 73, 80, 117 . $119,122,125,127,130]$. If we add up all papers from which we have an idea that an application has occurred we arrive at a total of 112 applications of maintenance optimization models, which is more than we initially expected.

Most case studies are written in cooperation with academic reliability researchers (68 out of the 112). Few originate from industry and if they do, often from an industrial research institution. Consultants are badly represented, giving the impression that application of maintenance optimization models was only possible by the people who developed them. This situation has changed with the emergence of commercial decision support systems for maintenance optimization.

Looking at the year of publication of all 112 papers gives the following picture:

$\begin{array}{cc}\text { year } & \text { number of publications } \\ -1969 & 1 \\ 1970-1974 & 4 \\ 1975-1979 & 17 \\ 1980-1984 & 20 \\ 1985-1989 & 45 \\ 1990- & 25\end{array}$

The fact that the majority of the papers has recently been published may indicate that a number of initial problems have been overcome and that more 
applications may be expected. It may also indicate that more publications outlets are available nowadays.

From the models applied, the age and block replacement models score high, but they are often applied in a somewhat different form. Other popular models are Markov decision models and the so-called delay time model (introduced by Christer \& Waller ${ }^{31}$ and reviewed in Baker \& Christer $^{4}$ ). It is noticeable that many papers describe a tailor-made model for the problems at hand. Apparently one often has to include problem specific factors.

There are several areas and industries in which the models have been applied; popular areas are equipment and vehicle replacements, inspection optimization, road maintenance and scheduling of maintenance of electric power stations.

Equipment overhauls comprises the largest group of applications (about thirty). Initial models were developed for this type of system and were closely connected to the economic replacement theory of capital goods. Another fruitful area is vehicle replacement (ten papers), considering buses, fork lift trucks, ambulances etc. One advantage in the case of vehicles is that the large amount of copies allows for data pooling. For equipment this is not always possible as similar equipment in different conditions may have quite a different failure pattern. Another problem is the constant appearance of new equipment, which makes historical records obsolete and puts other aspects on the replacement decisions. Optimizing inspections on equipment through the delay time model does prove to be successful.

A third and promising area for optimization is road maintenance. Here, a main problem is the determination of the amount and allocation of budgets to various projects. The first successful case study was presented in Ref. 46 (they quoted savings of millions of dollars!). Later some applications were carried out in the US. Today, US Congress proposes that all states have a pavement management system. ${ }^{50}$ Other countries followed, e.g., Worm \& Van Harten ${ }^{131}$ present a decision support system for the Dutch authorities. One reason behind the successes in this area is that a lot of data are collected in standard ways on deterioration. Hence the need arises to make use of this data in decision making. Furthermore, there is less time pressure on decision making compared to other maintenance organizations, and as funds have to be allocated between various projects in an objective and defendable way, there is a need for operations research models. Related applications concern water resources infrastructure, pipelines and railway track.

A fourth application area concerns the scheduling of overhauls of electric power stations. Kralj \& Petrovic $^{78}$ provide an overview and give the impression that several operations research methods have been applied.
We do not have much information about the military sector. Some papers ${ }^{17,44,103}$ suggest that the US forces have access to maintenance optimization models, but precise information is lacking. Some separate applications are manpower requirements planning, inspections in the nuclear industry and lighting maintenance. There are few papers on life cycle costing.

The problems encountered in applying maintenance optimization models mentioned in the case studies frequently concern data collection and analysis. As most papers advocate the technique, negative remarks on maintenance optimization are hard to find, except in the paper from Van Bommel \& Roes, ${ }^{120}$ which describes a failure to apply standard models and therefore (successfully) resort to failure analysis.

\subsection{Software packages for maintenance optimization}

The first packages for maintenance optimization ran on micro computers, like the HP 9845. They were developed by academics with an interest in practical applications. An example is the REGINA package, developed at Bradford University, which contains basic optimization models next to data analysis modules. Its use is described in Keller and Giblin. ${ }^{74}$ Another example is the FRANTIC package. ${ }^{127}$ Later, the personal computer became a popular platform for maintenance optimization software. Successful examples are the MAINOPT package, ${ }^{130}$ the AGE/CON, PERDEC and RELCODE packages, ${ }^{54}$ the KMOSS package from the Dutch KEMA, ${ }^{122}$ the OPTIMON package from the Dutch TNO, ${ }^{57}$ all including analytical models. MAINOPT is in fact the first package which does not originate from researchers, a fact which does show that theory has been picked up by others. Some packages, such as the MAROS $^{65}$ and MIRIAM ${ }^{80}$ packages primarily focus on availability assessment, but can also be used to optimize maintenance, although without analytical models. A typical aspect of the PC based packages is that they are used on a standalone basis and do not use data from databases, nor do they have connection with management information systems. They are especially suited for strategic questions concerning the maintenance concept. Packages which deal with daily operations are minicomputer or mainframe based. Examples are given in Refs 119, 43, 66, 46 and 52.

\subsection{General remarks}

One can make two remarks on the above. First of all, we are certainly missing some applications published. Secondly, applications of any particular operations research model are not frequently found in literature as it is mostly not sufficiently rewarding for practitioners to publish. If approaches are successful, 
companies are afraid of losing a competitive edge. Furthermore, scientific literature focuses on new aspects and the tenth application of the age replacement model will therefore not be published.

One may compare, for example, maintenance optimization theory with game theory, for which there may be even less applications. The main exception in operations research is linear programming which is widely used. In general, there is a long time gap between the emergence of a theory and its application. In the sequel of this paper we will investigate applications of maintenance optimization models in more detail.

\section{PROBLEMS IN APPLYING OPTIMIZATION MODELS}

In this section we discuss a number of problems which hamper optimization. It is difficult to state scientifically which reasons are dominant, so the selection is based on the authors own experiences with maintenance optimization models.

\subsection{Decision support systems needed to optimize maintenance}

Almost no maintenance optimization model yields results which only require simple calculations like the EOQ formula for the economic order quantity in inventory control (the economic order quantity $\mathrm{EOQ}=\sqrt{\{(2 A D) / v r\}})$. To determine the optimal maintenance policy one either has to use numerical integration or to solve sets of equations, except for some very specific cases for which graphical methods have been developed or analytical solutions exist.

Hence, in general, a software program is required and this should be ready at the appearance of the problem, unless the problem is repetitive. Such a program can be applied by either the developer, an inside or outside consultant or the problem owner (usually a maintenance or production engineer). The first applications published were in fact from academics who developed a software program. Later one sees professionals developing special decision support software. The problem owner is the ideal person to use the decision support system, yet he/she will often be unfamiliar with maintenance decision support systems, unless the problem is repetitive. The outside consultant is a costly alternative. Horton ${ }^{58}$ signals the problem of triggering an optimization, since before doing one, it is unclear what an optimization may save and whether a consultant is justified. Most companies, however, are too small to have a specialized inside maintenance optimization consultant. In any case, a consultant needs an excellent decision support system as well.
One main problem in developing a maintenance decision support system lies in the development of a generic modelling of maintenance problems such that standard models can be used. In fact one does not need a set of models with an user interface: one needs a generic structuring of maintenance problems, which indicates when which methods can be used and how all special aspects can be taken care of. The reason is that there is quite a diversity in maintenance problems and most of them are not repetitive. Application of models also requires a good formulation of the problem which is not easy since most concepts used (such as failure) allow various interpretations. To give a simple example, consider the system which consists of the front lights of a car. In this case one may define a system failure as either the failure of only one or of two lights. Both the distribution of the time to system failure and the cost of system failure depend heavily on the choice of definition. Furthermore, many models are not robust against violations of assumptions or misinterpretation of their concepts. A major shortcoming of most maintenance decision support systems is that they act like a black box. From the foregoing the dangers of such a black box will be clear: since each maintenance problem is likely to be different, it is only the user (and not the d.s.s.) who can validate the calculations and convince his/her management of their value.

For many models (except perhaps for the few multi-component models) there are no major computational problems, and hence there is no need for advanced computers to solve them. Developing a user-friendly system, however, takes much time and is therefore costly. Since the lifetime of personal computers and their operating system (in ten years six DOS versions and presently a switch to either Windows or OS/2) is short, such a program has to regain its initial costs within a few years.

Finally, there is always a threshold in using software systems. If they are not regularly used, there exists a serious danger of losing experience and finally they are put aside. Courses are often provided with packages, but even that is not enough. The average job duration for people can be quite small. Maintenance management has to be convinced to accept and demand quantitative methods as a basis for decision making. They will only do so if they have confidence in them. A focal point in the maintenance organization, familiar with operations research and computers, is therefore vital for the success of decision support systems.

\subsection{Data problems}

An essential part of a maintenance optimization model is the modelling of the deterioration and the occurrence of failures of a system in time in such a 
way that it is clear how both are influenced by the maintenance regime. Maintenance actions will only be effective and efficient if they specifically address the most relevant deterioration and failure mechanisms. Global statistics, like an average failure rate, will therefore be inappropriate for most maintenance actions, and apply only to complete replacements, which tend to be costly. Analysing data without knowing the underlying failure mechanisms can lead to totally wrong results (consider failures caused by wearout and by operator errors). Hence, data have to be collected under strict rules, defining failure and individual maintenance actions precisely, using a well-defined system-component structuring and indicating what events have happened on purpose. This is, however, mostly not the case, except perhaps in the airline industry. Maintenance information systems thus mainly store accounting information on events and there is a wide concern about the value of their data for engineering decision making. As collecting data requires a lot of effort, one should concentrate on the most relevant areas, which is a problem on its own. Exceptions are the condition monitoring programs, for which dedicated manpower is usually available.

An alternative is to make use of the knowledge contained in the maintenance technicians. This, however, requires a reformulation of most maintenance optimization models since it is very difficult to elicit probability distributions from people. ${ }^{124}$ Another aspect one should realize is that under good maintenance practices there are little failure data. If failures occur repeatedly, one may either change the system design or its operation to prevent failures, with the result that data collection has to start again.

Apart from problems with data on deterioration, one also has problems with cost data, especially with respect to the indirect costs. It is easy to quantify direct maintenance costs, but very difficult and sometimes subjective to quantify the benefits of maintenance. In the case of maintenance for production equipment one has to value the increase in reliability, availability or efficiency. The latter may be the easiest to judge. The first two are more difficult, especially if the equipment bears a complex relation with the final products (e.g., one may use spare equipment, or there may be over capacity, etc.); besides, all kinds of actions may be taken upon a failure to avoid really high costs. In those cases where extending system life is the maintenance objective one may set norms or ask economists to do a specific calculation. In all cases, decision support systems can help in reducing uncertainty on cost data. By experimenting with different values one gets an impression on the importance of data, which then helps in deciding whether more time should be spend on getting better data.

\subsection{The gap between theory and practice}

In many areas one complains about the gap between theory and practice. Hence we should concentrate on whether this gap is larger than normal. Here we focus on the following six aspects:

-maintenance optimization models are difficult to understand and to interpret. Many maintenance models have a stochastic nature, which is not only difficult to grasp by technicians and managers, but also difficult to interpret (the frequentist interpretation of probability is often hampered by many interfering circumstances). For example, a Markov decision model is far more difficult to understand and to interpret than a routing problem. Education of mechanical engineers traditionally focuses on deterministic approaches, which hampers effective use of reliability concepts. As maintenance is being underrated compared to other disciplines, academic support is limited;

-many papers have been written for maths purposes only. Mathematical analysis and techniques, rather than solutions to real problems, have been central in many papers on maintenance optimization models. Mathematical results on the existence and structure of optimal policies (e.g., control limit policies), however, are not appealing to practitioners: the structure of policies is generally determined by the problem setting. It is astonishing how little attention is paid either to make results worthwhile or understandable to practitioners, or to justify models on real problems or to consider data problems;

-companies are not interested in publication. Although many good ideas have been developed in industry, only a small amount has appeared in scientific literature. To have academics study industrial problems, they have to be exposed to them and to be rewarded if they solve them. Although academic freedom is a great thing, it does not force academics to tackle industrial problems. So companies should stimulate researchers by offering them problems and allowing them to publish their results;

-maintenance comprises a multitude of different aspects. Maintenance is a generic term referring to a variety of actions on all kinds of technical systems, deteriorating in various ways. Hence it is not surprising that there is no general model covering all possible cases. Despite the multitude of models, there is little knowledge on which models are suited for which practical problems nor which type of data are really driving problems. Instead of publishing new models one would be better unifying existing models and critically reviewing them on applicability;

-optimization is not always necessary. Maintenance optimization models indicate in principle the best decision given a certain problem and available information. The value of such a procedure (i.e., the 
savings because of a better decision making process) has to be balanced against the effort to apply the procedure and to get the required data. In some problem instances the potential savings are just too low to justify such sophisticated decision making. Furthermore, optimization often results in a lowering of the indirect costs, from which other parts of the organization, like operations, benefit, but not maintenance itself. Since this type of savings is less tangible, it is also less convincing to higher management;

optimization models often focus on the wrong type of maintenance. Finally, an often heard complaint is that maintenance optimization models focus too much on the wrong type of maintenance, i.e., planned revisions and overhauls. Although this type of maintenance was advocated in the 1950's and 1960's to prevent failures, it did not always prove to be effective. Efforts from manufacturers (e.g., design failures out) have further decreased the need for this type of maintenance. Furthermore, condition-based maintenance has replaced another part. Note that this complaint refers to the type of maintenance and not to the optimization models. It is true, however, that a large part of optimization models focuses on planned maintenance, though not always on revisions, but also on replacements and inspections. The reason is that in planning optimization methods have a well established role. Condition-based maintenance depends upon a measurable quantity which gives information about the actual state of systems. If there is such a quantity it will very likely provide better information than time or run-hours can offer as a prognostic variable and hence it will be a better basis for maintenance. Yet, such a condition quantity may be expensive to measure and may relate to some failure modes only. Furthermore, many of the condition indicators available so far (like vibration level), have a short-term prediction capacity only, which does not leave much room to save on costs by planning maintenance on appropriate moments.

\section{FUTURE PROSPECTS}

Despite all problems listed in the previous section, there is scope for maintenance optimization, because of two main reasons; the technological push and the economical necessity. First of all, computers are becoming cheaper and cheaper; not only in terms of computing power, but also with respect to clever registration devices. Integration of information systems implies that data on deterioration may be obtained from process monitoring systems. Furthermore, new developments in software technology enable better software development, with more intelligence embedded, in a shorter time span.
Optimization models are so far the only way in which scientifically justified statements on maintenance can be made.

Secondly, it is widely accepted that the amount of capital invested in technical systems will keep growing. Due to increased demands on performance of these systems (quality, reliability and safety) spending on maintenance is likely to grow as well, a trend which is visible in many companies. ${ }^{113}$ Contracting out maintenance also increases the need for a higher quality of decision making. Maintenance optimization models, embedded in decision support systems, provide an objective and quantitative way of decision making. One, which is defendable, and therefore very-well suited for group decision making, especially since it allows us to evaluate the economic consequences of decisions. One which is able to save substantial amounts of money, as Horton ${ }^{5 x}$ shows in his review of the use of MAINOPT. As maintenance optimization models are the only approach which combines reliability with economics in a quantitative way, they are in fact nothing more than extensions of the basic economic methods to justify maintenance. It is their role in the structuring of the decision process (pointing at which information is essential), the possibility to reduce uncertainty by investigating "what if' scenarios and the better insight into the effects of decisions across maintenance and production areas, which yields most benefits.

\section{CONCLUSIONS}

Maintenance optimization has flourished as a mathematical discipline within operations research and it is likely to do so in the future, considering the problems listed in recent reviews. Its impact on decision making within maintenance organizations is limited so far. Yet there are a number of case studies published which show that mathematical models are a good means to achieve both effective and efficient maintenance. As application tool technology (both soft- and hardware) is only recently becoming available at low costs and is rapidly developing, we expect that the near future will see many decision support systems incorporating maintenance optimization models. Economic pressure is likely to enforce the changes in culture that are necessary to make these packages standard tools for the modern maintenance manager.

\section{ACKNOWLEDGEMENT}

The author would like to acknowledge various people, especially Adriaan Smit and Cyp van Rijn from the Koninklijke/Shell-Laboratorium, Amsterdam for their contribution to the analysis reported in this paper. 


\section{REFERENCES}

1. Anderson, R.T. \& Neri, L., Reliability Centred Maintenance-Management and Engineering Methods, Elsevier Science Publishing Co. New York, 1990.

2. Andreou, S. \& Marks, D., Maintenance decisions for deteriorating water pipelines. J. Pipelines, 7 (1987) $21-31$.

3. Aspvall, B. \& Flom, S.J., Replacement strategies for subsurface safety valves. In Proc. Conf. on Autom. for Safety and Shipping in Offshore Operations (ASSOPO), Trondheim, Norway, 1985, pp. 191-194.

4. Baker, R.D. \& Christer, A.H., Review of delay-time OR modelling of engineering aspects of maintenance. Eur. J. Oper. Res., 73 (1994) 407-422.

5. Barlow, R.E. \& Proschan, F., Mathematical Theory of Reliability, John Wiley, New York, 1965.

6. Basker, B.A. \& Husband, T.M., Determination of optimal overhaul intervals and inspection frequencies-a case study. Micr. Elect. \& Rel., 17 (1978) 313-315.

7. Basker, B.A., Manan, A. \& Husband, T.M., Simulating maintenance work in an engineering firm: a case study. Micr. Elect. \& Rel., 16 (1977) 571-581.

8. Bassin, W.M., Increasing hazard functions and overhaul policy. In Proc. Rel. and Maint. Conf., Denver, USA, 7-9 July 1969, IEEE Press, Piscataway, NJ, pp. 173-180.

9. Ben-Ari, Y. \& Gal, S., Optimal replacement policy for multi-component systems: an application to a dairy herd. Eur. J. Oper. Res. 23 (1985) 213-221.

10. Bergman, B., On some recent advances in replacement theory. In Proc. Adv. Rel. Techn. Symp., 1980, pp. 363-372.

11. Bland, R.J. \& Knezevic, J., A practical application of a new method for condition-based maintenance. Maint. Management Int., 7 (1987) 31-35.

12. Blanks, H.S. \& Tordon, M.J., Optimum replacement of deteriorating and inadequate equipment. Qual. \& Rel. Engng Int. 2 (1986) 183-197.

13. Blundell, J.K \& Beard, K.W., Maintenance strategies for aero engines. In Proc. Ann. Rel. and Maint. Symp., Philadelphia, USA, 22-24 January 1985, IEEE Press, Piscataway, NJ, pp. 92-98.

14. Bosch, K. \& Jensen, U., Maintenance models: a survey. Parts 1 \& 2. OR Spektrum, 5 (1983) 105-118, 129-148 (in German).

15. Both, H., Maintenance and failure behaviour of technical systems: design and application of a simulation model. Ph.D. thesis, University of Eindhoven, The Netherlands, 1989 (in Dutch).

16. Brammer, K.W. \& Malmborg, C.J., A transient state model for predicting maintenance requirements. Engng Cost \& Prod. Econ., 11 (1987) 87-98.

17. Brandt, E.B. \& Limaye, D.R., MAD: mathematical analysis of downtime. Nav. Res. Log. Quat., 17 (1970) 525-535.

18. Brick, J.M., Michael, J.R. \& Morganstein, D., Using statistical thinking to solve maintenance problems. Quality Progress (Am. Soc. Qual. Cont.), 22 (1989) $55-60$.

19. British Standards Institution, BS3811 Glossary of maintenance terms in Terotechnology, BSI, London, 1984.

20. Chan, L.C. \& Miller, F.G., Optimization of fleet component exchange using the age replacement strategy. Maint. Management Int., 7 (1989) 155-163.

21. Chen, L.N. \& Toyoda, J., Maintenance scheduling based on two level hierarchical structure to equalize incremental risk. In Proc. 1989 Power Ind. Comp. Appl. Conf. (PICA '89), IEEE New York, USA, 1989.

22. Chevalier, C., Havart, J., Lannoy, A. \& Lyonnet, P., How to deduce a preventive maintenance period from reliability data. In 7 th Int. Conf. Rel. and Maint., Brest, France, 1990, pp. 698-702.

23. Chilcott, J.B. \& Christer, A.H., Maintenance modelling at the coal face. Int. I. Prod. Econ., 22 (1991) 1-11.

24. Cho, D.I. \& Parlar, M., A survey of maintenance models for multi-unit systems. Eur. J. Oper. Res., 51 (1991) 1-23.

25. Christer, A.H., Economic cycle periods for maintenance painting. Opl. Res. Q., 27 (1976) 1-13.

26. Christer, A.H. \& Doherty, T., Scheduling overhauls of soaking pits. Opl. Res. Q., 28 (1977) 915-926.

27. Christer, A.H. \& Goodbody, W., Equipment replacement in an unsteady economy. J. Opl. Res. Soc., 31 (1980) 497-506.

28. Christer, A.H. \& Keddie, E., Experience with a stochastic replacement model. J. Opl. Res. Soc., 36 (1985) 25-34.

29. Christer, A.H., MacCallum, K.L., Kobaccy, K., Bolland, J. \& Hesset, C., A systems model of underwater inspection operations. J. Opl. Res. Soc., 40 (1989) 551-565.

30. Christer, A.H. \& Scarf, P.A., A robust replacement model with applications to medical equipment. $J$. Opl. Res. Soc., 45 (1994) 261-275.

31. Christer, A.H. \& Waller, W.M., Reducing production downtime using delay-time analysis. J. Opl. Res. Soc., 35 (1984) 499-512.

32. Christer, A.H. \& Waller, W.M., An operational research approach to planned maintenance: modelling p.m. for a vehicle fleet. J. Opl. Res. Soc., 35 (1984) 967-984.

33. Concannon, K. \& Tudor, S., Railroads: visual interactive decision support systems streamlines maintenance operations. OR/MS Today, (1992) (Dec.) 40-44.

34. D'Aversa, J.S. \& Shapiro, J.F., Optimal machine maintenance and replacement by linear programming and enumeration. J. Opl. Res. Soc., 29 (1978) 759-768.

35. Davidson, D., An overhaul policy for deteriorating equipment. In Operational Research in Maintenance, (ed. A.K.S. Jardine) Manchester University Press, England, 1970.

36. Davis, C.F. \& Van Dine, C.P., Linear programming model for pavement management. In Transp. Res. Record, 1200 (1988) 71-75.

37. Day, J. \& George, L., Opportunistic replacement of fusion power systems parts. In Proc. Ann. Rel. and Maint. Symp., Los Angeles, USA, 26-28 January 1982, IEEE Press, Piscataway, NJ, pp. 271-277.

38. Dekker, R. \& Smeitink, E., Preventive maintenance at opportunities of restricted duration. Naval Res. Logistics, 41 (1994) 335-353.

39. De La Mare, R.F. Optimal equipment replacement policies. Report NCSR R21, UK Atomic Energy Authority, Nat. Centre of System Reliability, 1979.

40. Di-Fraia, L. \& Salemme, F., Improving the maintenance factor of lighting systems. Light-Res-Techn., 21 (1989) 107-109.

41. Edwin, K.W. \& Curtius, F., New maintenancescheduling method with production cost minimization via integer linear programming. Electrical Power \& Energy Systems, 12 (1990) 165-170.

42. Epstein, S. \& Wilamowsky, Y., A replacement 
schedule for multicomponent life-limited parts. Nav. Res. Log. Quat., 29 (1982) 685-692.

43. Esveld, C., Maintenance and railway track replacement assisted by computers. Rail Int. (1990) (June) 24-30 (in French).

44. George, L.L., Mahlooji, H. \& Hu, P.-W., Optimal replacement and build policies. In Proc. Ann. Rel. and Maint. Symp., Washington, USA, 23-25 January 1979, IEEE Press, Piscataway, NJ, pp. 147-152.

45. Germain, J., Interêt de la maintenance preventive conditionnelle. Achats et Entretien, 414-01-89 (1989) $43-46$.

46. Golabi, K., Kulkarni, R.B. \& Way, G.B., A statewide pavement management system. Interf., 12 (1982) 5-21.

47. Goodacre, J. \& Woodhouse, J., Proving the value of maintenance. In 8th National Computers in Maintenance Conference, London, 1986 pp. 3-3-1-3-3-14.

48. Gray, D.A., Airworthy: decision support for aircraft overhaul maintenance planning. $O R / M S$ Today, (1992) (Dec.) 24-29.

49. Haehling von Lanzenauer, C. \& Wright, D.D., Developing an optimal repair-replacement strategy for pallets. Nav. Res. Log. Quat. 25 (1978) 169-178.

50. Hagquist, R.F., Moving proposal. OR/MS Today, 20 (1993) 18-22.

51. Hajek, J.J., Chong, G.J., Haas, R.C.G. \& Phang, W.A., Knowledge-based expert system technology can benefit pavement maintenance. Transp. Res. Record, 1145 (1987) 37-47.

52. Hajek, J.J. \& Phang, W.A., Prioritization and optimization of pavement preservation treatments. Transp. Res. Record, 1216 (1989) 58-68.

53. Hall, H.D., Computer monitored inspection program (CMIP), a key to increased aircraft and personnel productivity. In Proc. Ann. Rel. \& Maint. Symp., Los Angeles. USA, 26-28 January 1982, IEEE Press, Piscataway, NJ, pp. 408-416.

54. Hastings, N.A.J. \& Jardine. A.K.S., Component replacement and the use of RELCODE. Micro. \& Rel., 19 (1979) 49-56.

55. Heising, C.D. \& Shwayri, N., Assessing the risk-costbenefits of electric power plant life extension. In Prob. Safety Assessm. and Risk Mgmt: PSA '87, Zurich, Switzerland, 1987, pp. 1042-1045.

56. Holland, C.W. \& McLean, R.A., Applications of replacement theory. AIIE Trans., 7 (1975) 42-47.

57. Hontelez, J.A.M., Burger, H.H. \& Wijnmalen, D.J.D., Optimum condition-based maintenance policies for deteriorating systems with partial information. Rel. Engng System Safety, 51 (1996) 267-274.

58. Horton, M., Optimum maintenance and RCM. In Proc. 3rd EsReDa Seminar on Equipment Ageing and Maintenance, Chamonix, France, 14-15 October 1992.

59. Jambulingam, N. \& Jardine, A.K.S., Life cycle costing considerations in reliability centered maintenance: an application to maritime equipment. Rel. Engng, 15 (1986) $307-317$.

60. Jardine, A.K.S., Solving industrial replacement problems. In Proc. Ann. Rel. and Maint. Symp., Washington, USA, 23-25 January 1979, IEEE Press, Piscataway, NJ, , pp. 136-141.

61. Jardine, A.K.S. \& Buzacott J.A., Equipment reliability and maintenance. Eur. J. Oper. Res., 19 (1985) $285-296$.

62. Jardine, A.K.S., Goldrick, T.J., \& Stender, J., The annual maintenance cost limit approach for vehicle fleet replacement. In Proc. Inst. Mech. Engng, 190 (1976) $71-80$.
63. Jardine, A.K.S. \& Hassounah, M.I., An optimal vehicle-fleet inspection schedule. J. Oper. Res. Soc., 41 (1990) 791-799.

64. Jardine, A.K.S. \& Kirkham, A.J.C., Maintenance policy for sugar refinery centrifuges. In Proc. Inst. Mech. Engng, 187 (1973) 679-686.

65. Jardine, I.J.A. \& Jackson, D., Risk assessment and optimization of a safety system using the MAROS simulation package. Qual. Rel. Engng Int., 5 (1989) $131-141$.

66. Jenkins, A.L., Gebbie, R.J. \& Jardine, A.K.S., A decision support system for equipment maintenance and replacement. Operational Research '87, (ed. G. Rand) North-Holland, Amsterdam, 1988, pp. 355-365.

67. Joshi, S. \& Gupta, R., Scheduling of routine maintenance using production schedules and equipment failure history. Computers \& Ind. Engng, 10 (1986) 11-20.

68. Kachashkin, S.A., A mathematical model of the preventive maintenance of multichannel transmission systems. Elektrosvyaz, 9 (1987) 45-48 (in Russian).

69. Kamath, A.R.R., Al-Zuhairi, A.M., Keller, A.Z. \& Selman, A.C., A study of ambulance reliability in a metropolitan borough. Rel. Engng, 9 (1984) 133-152.

70. Kazakov, A., Cook, W.D. \& Roll, Y., Measurement of highway maintenance patrol efficiency: model and factors. Transp. Res. Record, 1216 (1989) 39-45.

71. Kelly, A., Maintenance and its management. Conf. Commun., Monks Hill, England, 1989.

72. Keller, A.Z. \& Campbell, C.A., Development of automatic data collection systems for complex industrial plants. In Proc. Ann. Rel. and Maint. Symp., Orlando, USA, 25-27 January 1983, IEEE Press, Piscataway, NJ, pp. 187-192.

73. Keller, A.Z. \& Giblin, M.T., Optimal maintenance and replacement policies. In Adv. Rel. Techn. Symp., Bradford, UK, Atomic Energy Authority, 1984.

74. Khatami, A. \& George, K.P., Network level optimization-/prioritization of pavement rehabilitation. Transp. Res. Record, 1196 (1988) 224-233.

75. Kirkemo, F., Probabilistic strategy increases jacket in-service inspection efficiency. Offshore, (1990) (Dec.) $46-47$.

76. Knezevic, J., Required reliability level as the optimisation criterion. Maint. Management Int., 6 (1987) 249-256.

77. Kothari, D.P. \& Girotra, S.N., New optimal and reliable generator maintenance scheduling algorithm. IE(I) Journal-EL, 67 (1987) 171-172.

78. Kralj, B.L. \& Petrovic, R., Optimal preventive maintenance scheduling of thermal generating units in power systems - a survey of problem formulations and solution methods. Eur. J. Oper. Res., 35 (1987) $1-15$.

79. Lamson, S.T., Hastings, N.A.J. \& Willis, R.J. Minimum cost maintenance in heavy haul rail track. $J$. Opl. Res. Soc., 34 (1983) 211-223.

80. Lane, G.D., Malloy, K., Grundt, H.J. \& Sherwin, D.J., MIRIAM, software system for system effectiveness evaluations. In Proc. Rel.'85, Nat. Cent. Syst. Rel., Birmingham, UK, 1985, pp.4A/4/1-4A/4/7.

81. Lee J.H., Chang, S.H., Yoon, W.H. \& Hong, S.Y., Optimal test interval modeling of the nuclear safety system using the inherent unavailability and human error. Nucl. Engng \& Design, 122 (1990) 339-348.

82. Love, C.E., Rodger, A. \& Blazenko, G. Repair limit policies for vehicle replacement. INFOR, 5 (1982) $226-236$. 
83. Lund, J.R., Cost-effective maintenance and replacement scheduling. In Water Resources Infrastructure Needs Economic Finance, ASCE, Boston MA, USA. 1990 pp. 92-95.

84. Mahon, B.H. \& Bailey, R.J.M., A proposed improved replacement policy for army vehicles. Oper. Res. Quart., 26 (1975) 477-494.

85. Malik, M.A.K., Reliable preventive maintenance scheduling. AlIE Trans., 11 (1979) 221-228.

86. Mayer, R.R., Problems in the application of replacement theory. Management Sci., 6 (1960) 303-310.

87. McCall, J.J., Maintenance policies for stochastically failing equipment: a survey. Management Sci., 11 (1965) 493-524.

88. Mendelsohn, L., Modern lighting maintenance techniques can reduce energy costs. $E C \& M, 88$ (1989) $65-68$.

89. Mellichamp, J.M., Miller, D.M. \& Kwon, O.-J., The Southern company uses a probability model for cost justification of oil sample analysis. Interfaces, 23 (1993) $118-124$.

90. Moffat, J., Three case studies of operational research for the Royal Air Force. J. Oper. Res. Soc., 43 (1994) 955-960.

91. Monplaisir, M.H. \& Arumugadasan, N.S., Maintenance decision support: analysing crankcase lubricant condition by Markov process modelling. J. Oper. Res. Soc., 45 (1994) 509-518.

92. Mukhopadhyay, S.K. \& Johri, N.K., A case study on maintenance policy for transfer line heat exchangers. Maint. Management Int., 5 (1985) 201-207.

93. Mukhopadhyay, S.K. \& Srinivas Rao, M., A search for the optimal frequency of shutdown through computer simulation. Maint. Management Int., 7 (1987) $15-22$.

94. Naimanov, O.S., Determining optimum periodicity of capital overhauls of power units. Elektr. Stn. (USSR), 3 (1989) 52-56.

95. Nakajima, S., TPM--challenge to the improvement of productivity by small group activities. Maint. Management Int., 6 (1986) 73-83.

96. Nesbitt, D.M. \& Sparks, G.A., A computationally efficient system for infrastructure management with application to pavement management. (available from the author)

97. Perakis, A.N. \& İnözü, B., Optimal maintenance, repair and replacement for Great Lakes marine diesels. Eur. J. Oper. Res., 55 (1991) 165-182.

98. Pierskalla, W.P. \& Voelker, J.A., A survey of maintenance models: the control and surveillance of deteriorating systems. Nav. Res. Log. Quat., 23 (1979) 353-388.

99. Pintelon, L., Performance reporting and decision tools for maintenance management. Ph.D. thesis, K.U. Leuven, Belgium, 1990.

100. Pintelon, L.M. \& Gelders, L.F., Maintenance management decision making. Eur. J. Oper. Res., 58 (1992) 301-317.

101. Riddell, H.S., Life-cycle costing in the chemical industry: two case studies. Terotechnica, 2 (1981) 9-21.

102. Robyn, J.R., Watson, N. \& Mason, J.H., Application of practical methods for reliability engineering of maintenance program optimization. Trans. Am. Nucl. Soc. (USA), 56, suppl. 2 (1988) 26-27.

103. Rose, M., Determination of the optimal investment in end products and repair resources. Nav. Res. Log. Quart., 20 (1973) 147-159.
104. Rueda, A.G. \& Miller, F.G., A comparative analysis of techniques for determining bus replacement intervals. Maint. Management Int., 3 (1983) 271-286.

105. Rueda, A.G. \& Miller, F.G., A comparative analysis of techniques for determining component maintenance intervals in fleets. Maint. Management Int., 5 (1985) $279-295$

106. Sculli, D. \& Suraweera, A.W., Tramcar maintenance. J. Opl. Res. Soc., 30 (1979) 809-814.

107. Shamsi, U.M. \& Quimpo, R.G., Reliability analysis of water distribution networks. J. Inst. Engng India Part. CI, 68 (1988) 298-302.

108. Sharaf, E.A., Shahin, M.Y. \& Sinha, K.C., Analysis of the effect of deferring pavement maintenance. Transp. Res. Record, 1205 (1988) 29-35.

109. Sherif, Y.S., Reliability analysis: optimal inspection and maintenance schedules of failing systems. Micro. Reliab. 22 (1982) 59-115.

110. Sherif, Y.S. \& Smith, M.L., Optimal maintenance models for systems subject to failure-a review. Nav. Res. Log. Quart., 28 (1981) 47-74.

111. Sherwin, D.J. \& Lees, F.P., An investigation of the application of failure data analysis to decision-making in maintenance of process plants. In Proc. Inst. Mech. Engineers, 194 (1981) 301-319.

112. Sherwin, D.J. \& Jardine, A.K.S., Approximate optimisation of age and block renewal schedules using the beta distribution. In Proc. IFRIM Workshop. Eindhoven, 11-13 July 1994, Moret Ernst \& Young, Utrecht, The Netherlands.

113. Solomon, L., Essential elements of maintenance imporovement programs. In Proc. IFAC Workshop on Production Control in the Process Industry, Osaka, Japan, 29-30 October 1989 and Kariya, Japan, 1-12 November 1989, (eds E. Oshima \& C. van Rijn) Pergamon Press, Oxford, UK, pp. 195-198.

114. Steelandt, F.V. \& Gelders, L.F., The profit effectiveness of maintenance decisions: a case study. Int. J. Prod. Res., 19 (1981) 441-456.

115. Tabucanon, M.T. \& Garcia, B.D.R., Productivity improvement through preventive maintenance system: the case of a pulp and paper mill. Int. J. Policy Inf., 12 (1988) 99-108.

116. Turban, E., The use of mathematical models in plant maintenance decision making. Management Sci., 13 (1967) 342-358.

117. Ulusoy, G., Or, I., \& Soydan, N., Design and implementation of a maintenance planning and control system. Engng Cost and Prod. Econ., 24 (1992) 263-272.

118. Valdez Flores, C. \& Feldman, R.M., A survey of preventive maintenance models for stochastically deteriorating single unit systems. Nav. Res. Log. Quart., 36 (1989) 419-446.

119. Van Aken, J., Schmidt, A.C.G., Wolters, W. \& van der Vet, R.P., Reliability-based method for the exploitation of maintenance oppurtunities. In Proc. 8th Adv. Rel. Tech. Symp., 1984, pp. B3/1/1-B3/1/8.

120. Van Bommel, P., \& Roes, A.W., What is OR doing between the tracks? In Quantitative Methods in Management: Case studies of failures and successes, (eds C.B. Tilanus, O.B. De Gans, J.K. Lenstra) Wiley, Chichester, England, 1986.

121. Vandevender, C. \& Miller, F.G., Forecasting replacement of transit vehicle components using Markovian process modelling. Maint. Management Int., 7 (1989) $165-177$.

122. Van Gestel, P.J., KMOSS, a maintenance optimization 
support system. In Proc. Scand. SRE Symp., Studsvik. Sweden, 1990.

123. Vanneste, S.G. \& Wassenhove, L., An integrated and structured approach to improve maintenance. Eur. $J$. Oper. Res, 82 (1995) 241-257.

124. Van Noortwijk, J.A., Dekker, R., Cooke, R.M. \& Mazucchi, T.A., On the use of expert opinion for maintenance optimization. IEEE Trans. Rel., 41 (1992) $427-432$.

125. Van Rijn, C.F.H., Van Aken, J.A. \& Smit, A.C.J.M., EMMA, a maintenance manning assessment tool. In Proc. 3rd EsReDa seminar on Equipment Ageing and Maintenance, Chamonix, France, 14-15 October 1992.

126. Vered, G. \& Yechiali, U., Optimal structures and maintenance policies for PABX power systems. Oper. Res., 27 (1979) 37-47.

127. Vesely, W.E. \& Goldberg, F.F. FRANTIC-a computer code for time-dependent unavailability analysis. NUREG-0913 (US-National Regulatory
Commission): FRANTIC II, NUREG/CR-1924. Brookhaven National Laboratory, 1977, 1980.

128. Wels, H.C. \& Van Gestel, P.J., On an optimum maintenance policy for a high temperature superheater for a boiler. In Proc. 3rd EsReDa seminar on Equipment Ageing and Maintenance, Chamonix, France, 14-15 October 1992.

129. Wester, Ph., Optimization of the capital \& labour factors with regard to the maintenance of $\mathrm{HV}$ switchgear. In IEE Conf. Publ., 1 (1988) 26-31.

130. Woodhouse $\mathrm{J}$., Relating maintenance to production and company profits. In 6th. Nat. Conf. on Comp. for Maint. Management, Conf. Communications, Monks Hill, Farnham, UK, 1986.

131. Worm, J.M. \& Van Harten, A., Model based decision support for planning of road maintenance. Rel. Engng System Safety, 51 (1996) 305-316.

132. Zaino, N.A. Jr., Considerations in the use of optimal preventive maintenance policies. Qual. \& Rel. Engng Int. 3 (1987) 163-167. 